Document downloaded from:

http://hdl.handle.net/10251/157206

This paper must be cited as:

Martinez-Paredes, E.; Llorens, J.; Ródenas Martínez, L.; Savietto, D.; Pascual Amorós, JJ. (2019). Effect of early development on semen parameters and lifespan of rabbit males selected by high growth rate. Theriogenology. 139:72-80.

https://doi.org/10.1016/j.theriogenology.2019.07.014

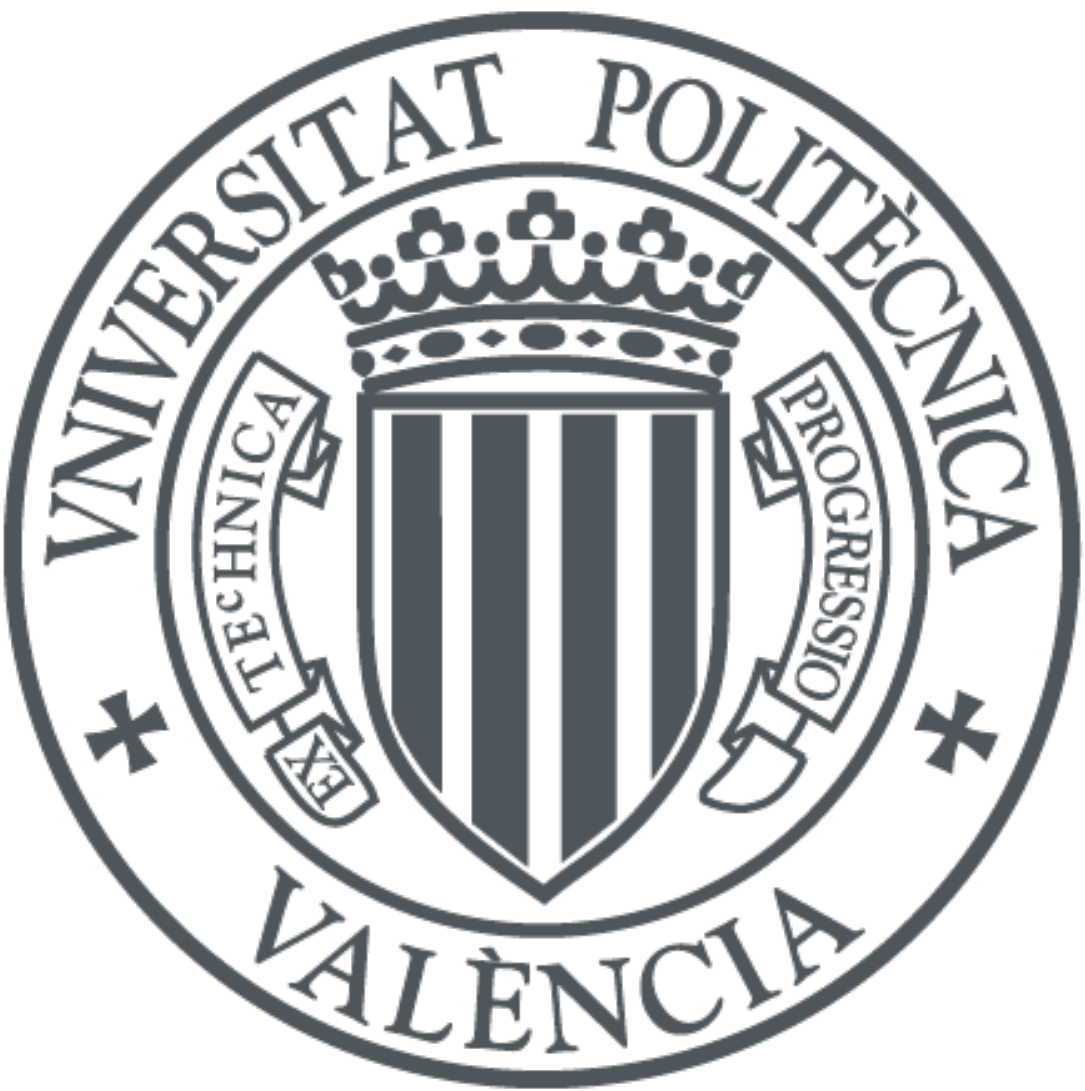

The final publication is available at

https://doi.org/10.1016/j.theriogenology.2019.07.014

Copyright Elsevier

Additional Information 


\section{Accepted Manuscript}

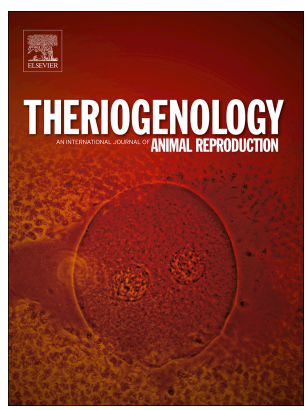

Effect of early development on semen parameters and lifespan of rabbit males selected by high growth rate

E. Martínez-Paredes, J. Llorens, L. Ródenas, D. Savietto, J.J. Pascual

PII:

S0093-691X(19)30324-3

DOI: https://doi.org/10.1016/j.theriogenology.2019.07.014

Reference: THE 15094

To appear in: Theriogenology

Received Date: 24 May 2019

Revised Date: 16 July 2019

Accepted Date: 16 July 2019

Please cite this article as: Martínez-Paredes E, Llorens J, Ródenas L, Savietto D, Pascual JJ, Effect of early development on semen parameters and lifespan of rabbit males selected by high growth rate, Theriogenology (2019), doi: https://doi.org/10.1016/j.theriogenology.2019.07.014.

This is a PDF file of an unedited manuscript that has been accepted for publication. As a service to our customers we are providing this early version of the manuscript. The manuscript will undergo copyediting, typesetting, and review of the resulting proof before it is published in its final form. Please note that during the production process errors may be discovered which could affect the content, and all legal disclaimers that apply to the journal pertain. 


\title{
Effect of early development on semen parameters and lifespan of rabbit males selected by high growth rate
}

\author{
Martínez-Paredes E. ${ }^{1}$, Llorens J. ${ }^{1}$, Ródenas L. ${ }^{1}$, Savietto D. ${ }^{2}$, Pascual J.J., ${ }^{1,3}$
}

${ }^{1}$ Instituto de Ciencia y Tecnología Animal, Universitat Politècnica de València, Camino de Vera s/n, 46022, Valencia, Spain

${ }^{2}$ GenPhySE, Université de Toulouse, INRA, INP, ENVT, Castanet Tolosan, France.

${ }^{3}$ Corresponding author: J.J. Pascual

jupascu@dca.upv.es

Phone: +34963877432

Fax: +34963877439

This study was supported by the Interministerial Commission for Science and Technology (CICYT) from the Spanish Government (AGL2017-85162-C2-1-R). 


\section{$1 \quad$ Abstract}

2 Life history theory suggests that different body development dynamics may influence

3 survival and future reproductive performance of organisms. The present work studied

4 how these dynamics could influence seminal traits and lifespan of rabbit males selected

5 for growth rate and intended for AI. To achieve this goal, a total of 550 rabbit males

6 were controlled from birth, evaluated both during the testing phase (four consecutive

7 weeks after reaching 147 days of life) and the productive phase (377 of them from the

8 end of the testing phase until 2 years of life). In order to obtain individuals with

9 different body development dynamics, we pre-selected males based on their live weight

10 (LW) at 0, 28, 63 and 147 days and on their average daily gain (ADG) between each

11 period (0-28, 28-63 and 63-147 days). Libido and main seminal traits (semen volume,

12 motility, concentration, and production, as well as normal apical ridge and

13 abnormalities of spermatozoa) were controlled during the testing phase. Semen volume,

14 motility and concentration were subsequently controlled during the productive phase, as

15 well as the length of the male life, calculated as the number of days a rabbit was present

16 at the farm between age 147 and day of death, culling or censoring; set to 2 years of

17 life). The birth weight, the ADG between 0-28 days and between 28-63 days were

18 positively related to some seminal parameters measured during the testing phase (semen

19 volume, concentration, production and motility; $\mathrm{P}<0.05)$, while the ADG between 63 -

20147 days was negatively related to the seminal productivity throughout the productive

21 life of the males (an increment of $10 \mathrm{~g}$ per day on ADG reduced the number of

22 profitable ejaculates by $4.9 \%$; $\mathrm{P}<0.05)$. In addition, a higher growth between $0-28$ and

23 between 63-147 days increased the risk of death or culling of males during the

24 productive phase $(\mathrm{P}<0.05)$. In conclusion, an adequate body development early in life

25 seems to have a positive effect on the degree of sexual maturity with which male rabbits 
26 begin their reproductive life, but reaching the reproduction onset with excessive weight

27 can reduce their reproductive performance and lifespan.

28 Keywords: Oryctolagus cuniculus, body development, growth rate, reproduction, 29 lifespan, semen quality. 


\section{Introduction}

31 In recent decades, the use of artificial insemination (AI) in rabbits has promoted an organisational improvement in the management of commercial farms, as well as the

33 appearance of specific centres for males destined for AI. These AI centres mainly breed

34 rabbit males from genetic lines selected for growth rate at fattening, which are used as

35 breeding males in the three-way crossing scheme. This scheme allows an effective

36 dissemination of the genetic material to optimise the productivity of commercial farms.

37 Despite the impact of these males on farm profitability, the scientific information on the proper feeding and raising management of male rabbits is still scarce. Nowadays we have information on the influence of nutritional requirements (both in rearing [1,2] and

40 productive periods [3]) and the physiological development of males [4,5] on their

41 fertility. We also have some estimation of the genetic parameters for seminal traits [6,7], but we lack information on how management practices in the early developmental age may influence the future reproductive life.

44 Furthermore, rabbit males (especially those selected for growth rate) have some 45 reproductive peculiarities which could be improved on (late reproductive onset, 46 moderate both sexual libido and sperm production, ...), justifying a better understanding 47 of the main factors that could affect their reproductive performance.

48 Some of the most important milestones concerning the reproductive physiological 49 development of male rabbits happens early in life, especially during fattening and 50 rearing periods [5]. In addition, the higher nutritional requirements of males selected for 51 growth rate during early growth development, until 14th weeks of life, are difficult to 52 cover compared to other animals [8,9]. In this sense, we hypothesise that the reproductive success of rabbit males (especially those from lines selected for growth 
54 rate) are influenced by the different development states achieved at key phases of their

55 developmental life (i.e. birth, weaning, and end of both juvenile and pubescent life).

56 If we look at other animal species, although selection for growth rate is positively

57 correlated to the size of reproductive organs, this selection criterion is negatively

58 correlated to seminal quality (in mice, Eisen and Johnson [10]; in pigs, Johnson et al.

59 [11]; in bulls, Kealey et al. [12]). In the case of breeding rabbits, there are few studies

60 that refer to the influence of body development of juveniles on the subsequent

61 reproductive performance of individuals as adults. Poigner et al. [13] observed that

62 heavier rabbit females at birth later showed larger litter size at their first parturition

$63(+12.4 \%)$, while Rommers et al. [14] reported a better reproductive performance (first

64 cycle) among heavier rabbit females at first mating, probably due to their greater degree

65 of maturity when first mated at a fixed age (14.5 weeks old). Recently, Martínez-

66 Paredes et al. [15] observed that fatter rabbit females at the beginning of their

67 reproductive life had smaller litter sizes and higher risk of being culled compared to the

68 lean ones. In rabbit males, Brun et al. [16], using two divergent lines of males selected

69 for growth rate, observed that some reproductive traits were related to LW. Lavara et al.

70 [7] observed the existence of negative genetic correlations between different seminal 71 traits, such as normal apical ridge (NAR) and motility, and the ADG of males selected

72 for growth rate. Altogether, these results indicate that an adequate body development of

73 rabbit males through lactation and the fattening and rearing periods may affect their

74 future reproductive performance.

75 For this reason, the present work aims to evaluate the effect that early development,

76 from birth to the end of rearing period, could have on the seminal performance of rabbit

77 males selected for growth rate addressed to AI, both in the training phase and

78 throughout their reproductive life, as well as in their lifespan. 


\section{2. Material and methods}

80 All experimental procedures were approved by the Animal Welfare Ethics Committee

81 of the Universitat Politècnica de València (UPV), following the Spanish Royal Decree

$821201 / 2005$ on the protection and use of animals for scientific purposes.

\section{2.1. Animals and housing}

84 We checked the LW of 550 male rabbits from the R line of UPV (selected for growth 85 rate from 28 to 63 days of age) at $0,28,63$ and 147 of life. In the four weeks following the $147 \mathrm{~d}$ of age, we evaluated the libido and some seminal parameters (once a week) on 550 males, pre-selected based on their LW and ADG variability at each weight control. After this testing phase, we selected 377 males to be followed up as potential reproduction males for 2 years of life.

90 To obtain the experimental males, 179 reproductive rabbit females from the $\mathrm{R}$ line, housed at a selection centre (El Adil Redondo S.L., Carrizo de la Ribera, León, Spain) were used. $\mathrm{R}$ females were artificially inseminated during five consecutive reproductive cycles, using the semen from $55 \mathrm{R}$ males from a different genetic origin. All the rabbit

94 females were inseminated at the same time (single batch), with a period between 95 inseminations of 42 days. Inseminations were carried out between February and 96 September.

\subsection{Experimental procedure}

Litters were sexed at birth to identify the males. A total of 1945 males were individually weighed at birth with a precision balance $( \pm 0.01 \mathrm{~g})$. Litter size (total and alive) and the

100 visual presence of milk in the stomach (milk spot) were also recorded. To identify the 101 males born, a $2 \times 12 \mathrm{~mm}$ glass chip (EI1001, Felixcan S.A., Spain) was injected 102 (subcutaneously) in the back of the animals, between both scapulae. We used a needle 103 disinfected in iodine and a syringe with a plunger. As most of the rabbit offspring had 
104 nursed just after birth, visually checked by the presence of a milk spot, we corrected

105 LW at birth from such animals by applying the following equation:

MS $(\mathrm{g})=-9.497+0.239 \cdot \mathrm{OLWB}+0.303 \cdot \mathrm{LSB}$

107 The estimated milk spot (MS) weight was a function of the offspring's LW at birth

108 (OLWB) with a milk spot and the litter size at birth (LSB). This equation was obtained

109 in a short trial performed on 120 offspring of the same line R, weighing both the mother

110 and their offspring before and after milking at day two after birth.

111 At 28 days old, the 1159 surviving male rabbits were weighed and re-identified with an

112 ink tattoo on the left ear. Litters were weaned at 36 days, transferring the mother to an

113 adjoining shed and leaving the weaned rabbits in the same cage in which they were

114 born.

115 Subsequently, the 1025 surviving males were weighed at 63 days of age. At that time, a

116 selection of the males that would be transferred to the AI centres was performed.

117 Selection was made considering the individual LW recorded and the ADG calculated in

118 the period 28-63 days. Males were chosen in each batch to obtain a population (604

119 males) that covered the maximum possible variability for the LW and ADG (Table 1) in

120 the different growth periods until this moment (at birth, between 0-28 days and between

121 28-63 days of life; corresponding to the lactation and the fattening period, respectively).

122 Once selected at 63 days of age, males were sent in an equitable manner to two different

123 locations (maintaining the variability profile in both ones). Half of them were sent to AI

124 centre A (Adil Redondo, Carrizo de la Ribera, León, Spain) and the other half to AI

125 centre Z (Zapiños, Abegondo, A Coruña, Spain).

126 Males were reared until 147 days of age (from 63 to 147 days), and the 550 males that

127 reached this age were weighed for the last time. During the next four weeks (testing 128 phase), the main seminal traits were controlled to determine the potential of each male 
129 to be used as semen producers at the AI centres. For each male, one ejaculate per week

130 was collected with the help of an artificial vagina, and semen volume, motility,

131 concentration and production were determined, as well as the NAR and abnormalities of

132 spermatozoa.

133 From 175 days up to a maximum of 2 years of life, 377 males were selected from the

134 initial 550 to be maintained at the AI centres. In this period, seminal traits such as

135 volume, motility and concentration were individually recorded twice a week. Productive

136 life represented the number of days a male was present at the AI centre from 175 days

137 old to its death, culling or censoring (set to 2 years).

138 All the males were fed with the same feeding programme during the trial. During

139 lactation, young males ate the same diets as their dams, with $16.8 \%$ crude protein $(\mathrm{CP})$

140 and $14.1 \%$ crude fibre $(\mathrm{CF})$ from 0 to 30 days of age, and with $15.0 \% \mathrm{CP}$ and $18.4 \mathrm{CF}$

141 from 30 to 36 days of age (pre-weaning). Once the males were weaned, the litter

142 received a fattening diet with $15.8 \% \mathrm{CP}$ and $14.7 \mathrm{CF}$ until 63 days of age (including 60

143 ppm tiamulin fumarate, $450 \mathrm{ppm}$ oxytetracycline and $158 \mathrm{ppm}$ neomycin sulphate to

144 avoid digestive disorders). From this moment until 147 days of age, the males were fed

145 with a rearing diet $(15.0 \% \mathrm{CP}$ and $17.5 \mathrm{CF})$. Finally, during the productive phase, the

146 diet offered had $16.5 \% \mathrm{CP}$ and $13.0 \% \mathrm{CF}$.

147 2.3. Semen evaluation

148 2.3.1. Testing phase (from 147 to 175 days of life)

149 Collected ejaculates with urine or any irregular aspect were discarded, and the rest

150 (successful attempts) were first observed to determine whether they contained gel

151 (immediately discarded to avoid spermatozoa agglutination). Subsequently, the volume,

152 concentration and sperm production were recorded according to the methods described

153 by Lavara et al. [6]. In brief, they are based on the visual assessment of ejaculation in a 
154 graduated tube followed by the sperm count in a counting chamber (Thoma-Zeiss cell)

155 under a microscope (phase contrast, $40 \times$ increase). Visual sperm motility was evaluated

156 under a microscope by a trained technician (percentage of spermatozoa showing

157 motility), after dilution of the complete ejaculate to $1 / 5$ in a tris-citric-acid-glucose

158 buffer. Motility of the ejaculate was presented as a binomial variable: 0 for samples

159 with percentage of motile spermatozoa below $65 \%$ or 1 , for samples with a percentage

160 of motile spermatozoa above $65 \%$.

161 NAR and percentage of abnormal spermatozoa were assessed after staining with eosin-

162 nigrosin mix. This procedure was similar to that described by García-Tomás et al. [17],

163 in at least 100 spermatozoa. The evaluation of abnormal forms was assessed according

164 to the criteria described by Barth and Oko [18], including the spermatozoa without

165 flagella.

166 2.3.2. Production phase (from 175 days to 2 years of life)

167 First, the aspect of each extracted ejaculate was evaluated, discarding those with a

168 yellowish colour and/or presence of urine, paste, gel, precipitates or blood. After that,

169 the volume of the ejaculate was measured in a graduated tube $( \pm 0.1 \mathrm{~mL})$ and visual

170 motility and concentration in a microscope after a 1:5 dilution with a tris-citric-glucose

171 diluent (250 mM of tris-hydroxymethylaminomethane, $83 \mathrm{mM}$ of citric acid, $50 \mathrm{mM}$ of

172 glucose; $\mathrm{pH}$ 6.8-7.0) were evaluated, both by the same trained technician in each AI

173 centre. Total collection attempts in the productive life was defined as the number of

174 times a male rabbit was taken to semen collection. Ejaculates were classified as

175 profitable when they presented adequate traits for use as commercial semen (a normal

176 aspect, an adequate visual motility above $65 \%$ and concentration). For each individual,

177 the percentage of profitable ejaculates was calculated in relation to the total collection

178 attempts. 
180 2.4.1. Libido "mating attempts" of young male rabbits during testing phase according to the body development traits

182 To evaluate the libido of young male rabbits, we implemented a series of multinomial

183 logistic regression models. Models contained two fixed effects, the batch (1 to 5) and

184 the destination farm (A or $\mathrm{Z}$ ) and a standardised co-variable related to the body

185 development (LW at 0, 28, 63 and 147 days of life, and ADG for the periods 0-28, 28-

18663 and 63-147). We used the R-software (version 3.5.0) and the "multinom" function of

187 the "nnet" package.

188 2.4.2. Seminal characteristics of young male rabbits during testing phase according to

189 the body development traits

190 To evaluate the seminal characteristics (volume, concentration, production, motility,

191 NAR, and spermatozoa morphological normality) of young male rabbits, we

192 implemented a series of linear mixed models. All models included the AI centre (A or

$193 \mathrm{Z}$ ), the batch (1 to 5), and the week of testing (1 to 4) as a fixed effect, the body

194 development traits (LW at 0, 28, 63 and 147 days old, and ADG for the periods 0-28,

195 28-63 and 63-147) as a covariate, and the permanent effect of each rabbit female $(p)$ and

196 the error term $(e)$ as random effects. Random effects were assumed to have an average

197 of zero and a variance of $\sigma_{p}^{2}$ for permanent, and $\sigma_{e}^{2}$ for the error term. We model the

198 variance-covariance among animals by using a compound symmetric structure for the

199 variance-covariance matrix of the residuals. The asymmetrical distribution of the

200 original data led to the logarithmic transformation of data from concentration and

201 production $\left(\log _{10} 10^{6}\right.$ spermatozoa per $\mathrm{mL}$ or ejaculate, respectively). As motility during

202 the testing phase was recorded as a binomial variable ( 0 , motile sperm below $65 \% ; 1$

203 motile sperm above 65\%), data were analysed under the GLIMMIX procedures of SAS 
204 [19] for binomial distributions. Solution provided odds values about the increase of

205 relative probability to be classified as 1 (motile sperm above 65\%) per unit of proposed

206 LW or ADG change. Finally, as NAR data presented a Poisson distribution, data were

207 analysed with six GLIMMIX procedures for Poisson distributions. Finally, semen

208 production and motility data during the testing phase were also analysed with the same

209 procedures described above, including the effect of the growth variables as main effect

210 (4 quartile classes) instead of as a covariate, for a better presentation of the obtained

211 results.

212 2.4.3. Seminal parameters of male rabbits (as adults) during production phase

213 according to the body development traits

214 For each of the variables average volume, average motility and profitable ejaculates

215 (both number and percentage) controlled during the productive phase, the data were

216 analysed with six GLM procedures of SAS [19]. Each of them included as fixed effects

217 the location, the batch, and as a covariate one of the growth variables to be evaluated. In

218 addition, profitable ejaculates data during the productive phase were also analysed with

219 the same GLM procedures described above. However, for an easy interpretation of

220 results, the body development variables were set as a fixed effect with four levels,

221 representing the four quantiles (quantile limits are in Table 1).

222

2.4.4. Productive lifespan of rabbit males (as adults) during the productive phase

223 according to the body development traits

224 Lifespan during the productive phase according to the body development traits (LW at

$2250,28,63$ and 147 days old, and ADG for the periods 0-28, 28-63 and 63-147) was

226 analysed using a series of Cox proportional hazard ratio models (one model for each

227 developmental trait). We first tested for the influence of the batch (1 to 5) or AI centre

228 the animal lived in (A or $\mathrm{Z}$ ) on the productive lifespan. As neither of these variables 
229 influence the productive life, they were not included in the models used to assess the

230 influence of the body development traits on the productive lifespan of the adult male

231 rabbits. As for the multinomial model and to avoid the scale effect, each development

232 trait was standardised before being included in the model. Hazard ratios, p-values and

233 the log likelihood ratio test for the model significance of each body developmental trait

234 are shown in Table 5. Kaplan-Meier estimations of survivorship (percentage of live

235 animals) according to the LW at 28 and at 147 days (the developmental traits explaining

236 the variability in the survival of male rabbits during their productive life) are in Figure

2374. 


\section{Results}

239 Means, standard deviations, coefficients of variation (CV), quartiles, minimum and

240 maximum values of LW, ADG and main traits controlled during the testing and

241 productive phases are listed in Table 1. Based on this natural variability, we could

242 correctly select individuals with a different dynamic of body development to test the

243 hypothesis that the early body development pattern influences lifespan and the seminal

244 characteristics of male rabbits. Concerning the body development traits, the observed

245 CV varied from 11 to $23 \%$.

246 For seminal characteristics (production and quality), the CV ranged from 17 to $96 \%$

247 during the testing phase and from 10 to $74 \%$ in the productive phase. This variability

248 allows us to correlate the possible differences in the seminal traits to the different

249 growth patterns. The same is applicable for productive lifespan in the productive phase;

250 the productive lifespan ranged from 7 to 550 days on production.

251 Libido "mating attempts" of young male rabbits during the testing phase according to

252 the body development traits are shown in Table 2. Having a different LW or ADG, at all

253 the controlled times, did not affect the number of successful AI attempts, evaluated as

254 the relative risk of changing from zero to one, two, three or four successful attempts.

255 The relationships between body development traits and seminal parameters during the

256 testing phase are shown in Table 3. LW at 0,28 and 63 days old, as well as the ADG

257 between the periods $0-28$ and $28-63$, influenced the semen characteristics. NAR was not

258 influenced by any developmental traits.

259 In summary, the increment (per each $10 \mathrm{~g}$ ) on the LW at 0 days resulted in a higher

260 volume, concentration, production and spermatozoa motility $\left(+0.02 \mathrm{~mL},+1.1 \times 10^{6}\right.$

261 spermatozoa per $\mathrm{mL},+1.1 \times 10^{6}$ spermatozoa per ejaculate and an odds ratio of 1.13 , the

262 likelihood of observing ejaculates with an adequate motility ( $>65 \%)$ being $13 \%$ higher, 
263 respectively; $\mathrm{P}<0.05)$. In fact, semen production linearly increased with $\mathrm{LW}$ at 0 days of

264 male rabbits (Figure 1a) and motility was significantly lower for the males weighing

265 less than $65 \mathrm{~g}$ at birth (Figure 2a).

266 An increase in ADG in the period 0-28 days of $10 \mathrm{~g}$ represented an improvement in

267 semen concentration, production and motility of $+1.3 \times 10^{6}$ spermatozoa per mL,

$268+1.4 \times 10^{6}$ spermatozoa per ejaculate and a likelihood of $+56 \%$ of having an adequate

269 spermatozoa motility $(>65 \%)$, respectively; $\mathrm{P}<0.05$. The same pattern was observed for

270 the ADG between 28-63 days and for the measures of LW at 28 and 63 days. In fact,

271 both semen production (Figure 1b) and motility (Figure 2b) linearly increased with the

272 ADG of males in the period 0-28 days; males showing an ADG between 0-28 days

273 below $21 \mathrm{~g}$ per day had a diminished semen production and motility in the testing

274 phase.

275 For the ADG in the period 28-63, the improvements on semen concentration,

276 production and motility per each $10 \mathrm{~g}$ of increment was $+1.2 \times 10^{6}$ spermatozoa per $\mathrm{mL}$,

$277+1.3 \times 10^{6}$ spermatozoa per ejaculate and a $38 \%$ greater likelihood of having adequate

278 motility, respectively; $\mathrm{P}<0.05$ ). In this case, semen production (Figure $1 \mathrm{c}$ ) and motility

279 (Figure 2c) seem to achieve the highest values for those males showing an ADG in the

280 period 28-63 greater than $63 \mathrm{~g} / \mathrm{d}$, although they have no significant differences

281 compared to some other ADG quartiles. At the end of the rearing period (147 day), an

282 increase in LW of $1000 \mathrm{~g}$ only improved the semen volume $(+0.06 \mathrm{~mL}, \mathrm{P}<0.05)$,

283 although this was not relevant in practice.

284 Concerning the influence of LW and ADG on the volume, motility and the number and 285 percentage of profitable ejaculates (Table 4), only the number and percentage of 286 profitable ejaculates were influenced. In this sense, an increment of LW at 147 days of 1

$287 \mathrm{~kg}$ represented a reduction of 6 percentage points in the percentage of profitable 


\section{ACCEPTED MANUSCRIPT}

288 ejaculates $(\mathrm{P}<0.05)$, while animals having gained, on average, $10 \mathrm{~g}$ per day more in the 289 period 63-147 had a lower number and percentage of profitable ejaculates $(-10.1$ and $2904.9 \%$, respectively; $\mathrm{P}<0.05)$ throughout their productive life. In fact, rabbit males that

291 showed a growth rate above $29 \mathrm{~g} / \mathrm{d}$ had the smallest number of profitable ejaculates

292 during the productive phase (Figure 3).

293 Finally, Figures 4 and Table 5 show the influence of early development traits on the

294 hazard ratio of death or culling during the productive phase. We observed that an 295 increase in one standard deviation unit on LW at 28 or at 147 days, as well as for the 296 ADG in the periods 0-28 and 63-147, all increased the risk of leaving the herd by +14.6 , $297+17.5,+14.6$ and $+16.2 \%$, respectively $(\mathrm{P}<0.05)$. These values return a median survival 298 life for theoretical males weighing 650, 750 and $850 \mathrm{~g}$ at 28 days old of 65,56 and 51 299 weeks of age, respectively (Figure 4a), and for those weighing 4.6, 4.9 and $5.2 \mathrm{Kg}$ at 300 rearing end would be 60, 53, and 48 weeks of age, respectively (Figure 4b). 
302 For an adequate assessment of the possible effect of the different degrees of 303 development of the males at different times in their early life, it was essential to build a 304 population of rabbit males that had a wide variability in their growth traits (Table 1).

$305 \mathrm{CV}$ values obtained in this work show a wide range for the different growth variables 306 controlled (from 11 to 23\%). In fact, the standard deviation observed with 550 males

$307(6.9 \mathrm{~g} / \mathrm{d})$ for $\mathrm{ADG}$ during the fattening period was similar to that obtained for a 308 population of 12,908 rabbit males of this same genetic line $(6.9 \mathrm{~g} / \mathrm{d}$; [7]). In addition, 309 mean values of growth traits were very close to the median values and there was, in 310 general, a good equidistance between quartiles on both sides, denoting symmetry in data 311 distribution. These results seem to confirm that the needed population structure was

312 achieved. On the other hand, the average LW and ADG values obtained in this work 313 were slightly higher than those reported in other studies with selected males from this 314 same genetic line $[1,7,20]$. This fact could be related to different climatic and 315 environmental conditions, as well as differences in the generation of selection in the 316 animals in the different trials.

317 Regarding the semen traits, data variability was very high both in the testing and 318 production phases (with $\mathrm{CV}$ values up to $96 \%$ ). The same general conclusion was 319 reached by Lavara et al. [7] for the semen traits in rabbit males of R line (with CV 320 values up to $78 \%$ ). These authors, using $\mathrm{R}$ rabbit males after the testing phase, presented 321 similar values to those obtained in our work for NAR during the testing phase and 322 semen motility during the production phase, but lower for the percentage of abnormal 323 spermatozoa (17.0 vs. $34.5 \%)$ and higher motility (65.0 vs. $42.0 \%)$ than our males in 324 the testing phase. Moreover, Pascual et al. [1] observed similar results on motility and 325 NAR values, but a lower number of ejaculates and abnormal spermatozoa, as well as 
326 higher semen volume, concentration and production during testing phase $(-1.3,-27,8 \%$,

$327+0.31 \mathrm{~mL},+113 \times 10^{6}$ spermatozoa per $\mathrm{mL}$ and $+144 \times 10^{6}$ spermatozoa per ejaculate,

328 respectively). Differences between trials could be due to the different environmental

329 conditions, maturity degree of the rabbit males used and the use of different assessment

330 techniques in the case of motility (CASA vs. visual).

331 The testing phase is commonly used by AI centres to determine which rabbit males will

332 be chosen for semen production. Libido is a key behavioural trait in the choice of rabbit

333 males to be destined to AI. The results of the present work have showed that early

334 growth traits did not significantly affect the number of realised attempts of males during

335 the testing phase. However, higher ADG during the fattening period seems to be

336 associated with increased probability of a higher number of attempts $(\mathrm{P}<0.10)$. Pascual

337 et al. [1] observed that the $\mathrm{R}$ rabbit males that adequately cover their nutritional

338 requirements during the different phases of early development, also showed a high

339 number of ejaculates during their testing phase $(+0.40$ and +0.28 ejaculates for males

340 reared on autumn and spring seasons, respectively). These results could indicate that a

341 proper growth during the first steps of the life could contribute to achieve sooner an

342 adequate maturity degree, with a better libido, at the beginning of the reproductive life,

343 although further studies would be needed to confirm it.

344 Corroboration of existence of a relationship among body development traits and the

345 seminal parameters, both in the short and long term, would allow to anticipate and

346 improve the choice of the most adequate rabbit males to be destined to AI. To have a

347 higher LW at birth had a slightly positive effect on some seminal parameters at the

348 testing phase (volume, concentration, production and motility), especially for those

349 weighing over 65 g. Fortun [21] observed that the development and multiplication of

350 the primordial germ cells and of the primordial follicles already occurs during own 
351 gestation. In rabbit females, Poigner et al. [13] observed that females born with a

352 heavier weight produced more offspring as adults than lighter ones. However, the

353 positive linear effect of a heavier weight at birth at early reproductive live of rabbit

354 males seem to disappear after during the production period. Therefore, an adequate

355 foetal nutrition and development could contribute to a better semen performance at early

356 reproductive life, but without positive effects in long terms, so it does not seem to be

357 one of the most key development traits in defining future male performance.

358 Growth during the first two months of life had a strong influence on some seminal traits

359 (motility and semen concentration and production) during testing phase. Rabbit males

360 with patterns of low growth (up to 21 and $53 \mathrm{~g}$ per day during lactation and fattening

361 periods, respectively) showed clearly lower semen production with a worse motility at

362 early reproductive life. These results may be due to the fact that important changes in

363 physiological [22] and reproductive (seminiferous tubules; [5]) development take place

364 during lactation and fattening, and lighter males probably did not reach the testing phase

365 with a sufficiently mature reproductive status. Pascual and Pla [23], comparing R

366 rabbits differing in 16 generations of selection for growth rate during fattening,

367 observed that less selected animals (with lower growth rate both during lactation and

368 fattening period) showed a lower physiological development at the end of the fattening

369 period (-13\% liver, $-8 \%$ kidneys and $-7 \%$ dissectible fat). In addition, rabbit males

370 showing low growth until 63 days of life may be due to their requirements not being

371 properly covered. Pascual et al. [1] observed worse semen traits during the testing phase

372 in those rabbit males that did not correctly cover their nutritional needs from 9 to 14

373 weeks of life. However, the negative effects of lower growth in the first 63 days of age

374 on semen performance disappeared in the production phase. These results seem to

375 indicate that an early underdevelopment could be delaying the reproductive capacity of 
376 young males, so management programmes (standardised litter size during lactation,

377 specific diets during fattening...) that will ensure the necessary provision of nutrients to

378 the males during the first two months of life would be advisable.

379 Both ADG during rearing period and LW at rearing end had no relevant effects on

380 semen traits during the testing phase. However, greater growth during the rearing period

381 and heavier weight at the beginning of their reproductive life had negative effects on the

382 number and percentage of profitable ejaculates obtained throughout the productive life

383 of the males. These negative linear effects associated with the rearing growth could be

384 related to an inappropriate feeding adjustment of programmes during this period.

385 During the rearing period, when using commercial diets provided ad libitum, rabbit

386 males from parental lines tend to over-consume [1], which may lead them to a level of

387 fatness higher than that desirable for the onset of the reproductive phase. Recently,

388 Pascual et al. [24,2] found that when fitting the nutritional requirements and providing a

389 constant daily supply of nutrients to rabbit males selected for growth rate,

390 improvements in some sperm morphological characteristics and the fertility rate of their

391 semen are achievable. In males, Du Plessis et al. [25] also observed that being

392 overweight could sometimes be associated with an increase in abnormal spermatozoa

393 and a high risk of fertility problems.

394 Finally, lifespan improvement of breeding rabbits should be one of the objectives of

395 rabbit production, as it is usually associated with an improvement in both farm

396 efficiency and the welfare and health of the animals. In the rabbit males used for AI,

397 reaching a higher life expectancy is mainly due to their better adaptability to the farm

398 environmental conditions and to their adequate semen production. In our work, higher

399 growth rates during lactation and rearing periods were associated with a higher risk of

400 death or culling during the production phase of rabbit males. A hypothesis for this 
401 higher risk could be related to getting and sustaining an excessive level of fatness in

402 rabbit males during the production phase. During lactation, the total number and size of

403 adipocytes are defined, favoured by energy intake coming from fat [26]. Rabbit milk

404 has a high fat content compared to that of other mammals [27], and young rabbit males

405 showing higher ADG would consequently suckle higher amounts of fat from their

406 mother's milk. A higher number of adipocytes would help the excessive deposition of

407 fat when the nutrition requirements are not fitted in the long term. In fact, the energy

408 requirements for growth and maintenance during the rearing period are scarce, and

409 excessive energy intake could easily occur, which would increase the risk of rabbit

410 males reaching the beginning of their reproductive life with a level of body reserves

411 above that recommended at this age. In rabbits, Maertens [28] proposed fitting the

412 feeding level to daily requirements to reduce the troubles associated to fatness.

413 Recently, some works $[29,15]$ have confirmed that non-adequate body condition around

414 the first mating had clear negative effects on the future reproduction performance and

415 lifespan of young rabbit females. Therefore, it seems that higher level of body reserves

416 at the onset of reproductive life could lead rabbit males to an increased risk of suffering

417 health troubles and/or reducing their libido or semen production or quality, which could 418 increase their risk of death and culling. 
419 5. Conclusions

420 From these results, it could be concluded that early development of the rabbit males,

421 selected by growth rate during fattening and intended for AI, influences their semen

422 production and quality in the short and long term as well as their lifespan. A greater

423 growth development of the rabbit males until the end of their fattening period seems to

424 have a positive effect on the degree of sexual maturity with which they begin their

425 reproductive life, improving aspects such as libido, spermatozoa motility and seminal

426 production, but not in the long term. However, the rearing period seems to be key to

427 achieving a long and productive reproductive life. Reaching the reproduction onset with

428 an excessive weight seems to reduce the reproductive performance and lifespan of

429 rabbit males. Therefore, fitting the feeding requirements during the final phase of

430 growth, when the energy needs for growth are reduced, could be an adequate

431 management recommendation for the young reproductive rabbit males from paternal

432 lines.

433

\section{6. Acknowledgements}

435 The authors would like to thank José Manuel Arias, owner of the selection centre El 436 Adil Redondo S.L., (Carrizo de la Ribera, León, Spain), and his team for their help, as 437 without their collaboration this work could not have been carried out. This study was 438 supported by the Interministerial Commission for Science and Technology (CICYT) of 439 the Spanish Government (AGL2017-85162-C2-1-R). 
441 [1] Pascual JJ, García C, Martínez E, Mocé E, Vicente JS. Rearing management of 442 rabbit males selected by high growth rate: the effect of diet and season on semen 443 characteristics. Reprod Nutr Dev 2004; 44: 49-63.

444 [2] Pascual JJ, Marco-Jiménez F, Martínez-Paredes E, Ródenas L, Fabre C, Juvero MA, 445 Cano JL. Feeding programs promoting daily feed intake stability in rabbit males reduce 446 sperm abnormalities and improve fertility. Theriogenology 2016; 86 (3): 730-737.

447 [3] Castellini C. Semen production and management of rabbit bucks. Proceedings of the 9th World Rabbit Congress; 2008 June 10-13; Verona, Italy; p. 265-278.

449 [4] Lavara R, Mocé E and Vicente JS 2003. Buena práctica de inseminación artificial: I. 450 Preparación de dosis seminales. Los factores responsables de la variación de los 451 resultados de fertilidad y prolificidad de la IA. Boletín de Cunicultura; 128: 14-23.

452 [5] García-Tomás M, Sánchez J, Piles M. Postnatal sexual development of testis and 453 epididymis in the rabbit: Growth and maturity patterns of microscopic markers. 454 Theriogenology 2008; 71: 292-301.

455 [6] Lavara R, Vicente JS, Baselga M. Genetic parameter estimates for semen production 456 traits and growth rate of a patern rabbit line. J Anim Breed Genet 2011; 128: 44-51.

457 [7] Lavara R, Vicente JS, Baselga M. Estimation of genetic parameters for semen 458 quality traits and growth rate in a paternal rabbit line. Theriogenology 2012; 78: 567459575.

460 [8] Pascual JJ. Nutrición de machos destinados a inseminación artificial. Proceedings of 461 the II Jornadas Internacionais de Cunicultura; 2002 Oct 11-12; Vila Real, Portugal; p. 462 197-212.

463 [9] Marín-García PJ, López-Luján MC, Ródenas L, Martínez-Paredes E, Blas E, 464 Pascual JJ. Do high growth-rate rabbits prefer diets richer on amino acids than those 
465 recommended? Proceedings of the 69th Annual Meeting of the European Federation of

466 Animal Science (EAAP 2018); 2018 Aug 31; Dubrovnic, Croatia; p. 585.

467 [10] Eisen EJ, Johnson BH. Correlated responses in male reproductive traits in mice 468 selected for litter size and body weight. Genetics 1981; 99: 513-24.

469 [11] Johnson RK, Eckardt GR, Rathje TA, Drudik DK. Ten generations of selection for 470 predicted weight of testes in swine: direct response and correlated response in body 471 weight, backfat, age at puberty, and ovulation rate. J Anim Sci 1994; 72:1978-88.

472 [12] Kealey CG., Macneil MD, Tess MW, Geary TW, Bellows RA 2006. Genetic 473 parameter estimates for scrotal circumference and semen characteristics of Line 1 474 Hereford bulls. J Anim Sci 2006; 84:283-90.

475 [13] Poigner J, Szendrö Z, Lévai A, Radnai I, Biró-Nemeth E. Effect of birth weight 476 and litter size at suckling age on reproductive performance in does as adults. World $477 \quad$ Rabbit Sci 2000; 8 (3): 103-109.

478 [14] Rommers JM, Meijerhof R, Noordhuizen JPTM, Kemp B. Relationships between 479 body weight at first mating and subsequent body development, feed intake, and 480 reproductive performance of rabbit does. J Anim Sci 2002; 80 (8): 2036-42.

481 [15] Martínez-Paredes E, Ródenas L, Pascual JJ, Savietto D. Early development and 482 reproductive lifespan of rabbit females: implications of growth rate, rearing diet and 483 body condition at first mating. Animal 2018; 12 (11): 2347-2355.

484 [16] Brun JM, Theau-Clément M, Esparbié J, Falières J, Saleil G, Larzul C. Semen 485 production in two rabbit lines divergently selected for 63-d body weight. 486 Theriogenology 2006; 66: 2165-2172.

487 [17] García-Tomás M, Sánchez J, Rafel O, Ramon J, Piles M. Variability, repeatability 488 and phenotypic relationships of several characteristics of production and semen quality. 489 Anim Reprod Sci 2006; 93: 88-100. 
490 [18] Barth AD, Oko RJ. Abnormal morphology of bovine spermatozoa. Iowa State

491 University Press, 1989.

492 [19] SAS. SAS/SAT User's Guide (Release 9.1). SAS Inst. Inc. Cary NC, USA, 2002.

493 [20] Lavara R, Baselga M, Marco-Jiménez F, Vicente JS. Embryo vitrification in

494 rabbits. Consequences for progeny growth. Theriogenology 2015; 84: 674-680.

495 [21] Fortun JE. Ovarian follicular growth and development in mammals. Biol Reprod 496 1994; 50: 225-232.

497 [22] Deltoro J, López AM. Allometric changes during growth in rabbits. J Agric Sci 498 1985; 105: 339-346.

499 [23] Pascual M, Pla M. Changes in carcass composition and meat quality when 500 selecting rabbits for growth rate. Meat Sci 2007; 77 (4): 474-481.

501 [24] Pascual JJ, Marco-Jiménez F, Martínez-Paredes E, Ródenas L, Martínez-Talaván 502 A, Fabre C, Martín E, Juvero MA, Cano JL. El uso de programas de alimentación en 503 conejos reproductores que regulan la ingestión reduce las anormalidades espermáticas y 504 mejora la fertilidad. Proceedings of the XL Symposium de Cunicultura ASESCU; 2015 505 May 28-29; Santiago de Compostela, Spain; p. 70-74.

506 [25] Du Plessis SS, Cabler S, McAlister DA, Sabanegh E, Agarwal A. The effect of 507 obesity on sperm disorders and male infertility. Nat Rev Urol 2010; 7: 153-161.

508 [26] Šnajder D, Perić Kačarević Ž, Grgić A, Bijelić N, Fenrich M, Belovari T, Radić R. 509 Effect of different combination of maternal and postnatal diet on adipose tissue 510 morphology in male rat offspring. J Matern Fetal Neonatal Med 2018. Doi: $511 \quad 10.1080 / 14767058.2017 .1419181$.

512 [27] Pascual J, Cervera C, Blas E, Fernández-Carmona J. Effect of high fat diets on the 513 performance, milk yield and milk composition of multiparous rabbit does. Anim Sci 514 1999; 68(1): 151-162. 
515 [28] Maertens L. Feeding systems for intensive production. In: De Blas C, Wiseman J,

516 editors. Nutrition of the Rabbit, Wallingford, UK: CABI Publishing; 2010, p. 253-266.

517 [29] Martínez-Paredes E, Ródenas L, Martínez-Vallespín B, Cervera C, Blas E,

518 Brecchia G, Boiti C, Pascual JJ. Effects of feeding programme on the performance and

519 energy balance of nulliparous rabbit does. Animal 2012; 6: 1086-1095. 
Table 1. Main descriptive values of population used in the experiment (550 males until testing phase and 377 males for production phase).

\begin{tabular}{lcccccccc}
\hline Variables & \multicolumn{9}{c}{ Lower } & Upper \\
LW and ADG $(\mathrm{g})$ & Mean & SD & Min & Q & Median & Q & Max & CV \\
\hline LW 0 days & & & & & & & & \\
LW 28 days & 65.0 & 11.1 & 34.3 & 57.8 & 64.9 & 72.1 & 102.0 & 17.15 \\
LW 63 days & 765 & 157 & 318 & 662 & 764 & 870 & 1240 & 20.53 \\
LW 147 days & 2785 & 319 & 1696 & 2586 & 2800 & 3012 & 3640 & 11.45 \\
ADG 0-28 days & 4909 & 530 & 3095 & 4580 & 4905 & 5260 & 6495 & 10.79 \\
ADG 28-63 days & 25.01 & 5.43 & 9.75 & 21.45 & 25.00 & 28.62 & 41.16 & 21.72 \\
ADG 63-147 days & 57.69 & 6.92 & 30.51 & 53.09 & 58.17 & 62.91 & 73.89 & 11.99 \\
& 25.28 & 5.74 & 8.60 & 21.64 & 25.15 & 28.76 & 42.85 & 22.69
\end{tabular}

Semen traits during testing phase ${ }^{1}$

Ejaculates (n)

Average volume $(\mathrm{mL})$

Average motility $(\%)^{1}$

Average concentration $\left(\mathrm{spz} \times 10^{6} / \mathrm{mL}\right)$

Average production (spz $\times 10 \%$ ejaculate)

Average NAR (\%)

Average spz abnormalities (\%)

Traits during production phase ${ }^{2}$

Productive life (days)

Collection attempts (n)

Extracted ejaculate (n)

Average volume ( $\mathrm{mL})$

Average motility $(\%)^{3}$

Profitable ejaculates (n)

Profitable ejaculates (\%)

$\begin{array}{cccccccc}2.68 & 1.43 & 0.00 & 2.00 & 3.00 & 4.00 & 4.00 & 53.29 \\ 0.60 & 0.28 & 0.00 & 0.40 & 0.58 & 0.75 & 1.77 & 46.49 \\ 42.01 & 26.42 & 0.00 & 23.17 & 45.00 & 67.50 & 82.00 & 62.89 \\ 123.8 & 100.9 & 0.0 & 50.9 & 102.0 & 165.8 & 817.5 & 81.51 \\ 79.4 & 76.2 & 0.0 & 22.2 & 57.5 & 110.7 & 530.4 & 96.04 \\ 89.5 & 15.5 & 19.9 & 90.1 & 96.0 & 98.0 & 100.0 & 17.25 \\ 34.50 & 20.20 & 1.56 & 17.80 & 30.01 & 48.14 & 90.10 & 58.56\end{array}$

$\begin{array}{llllllll}351.2 & 198.2 & 7.0 & 155.0 & 395.0 & 546.0 & 550.0 & 56.42\end{array}$

$\begin{array}{llllllll}88.1 & 53.1 & 2.0 & 38.0 & 88.0 & 144.0 & 182.0 & 60.25\end{array}$

$\begin{array}{llllllll}83.6 & 52.3 & 1.0 & 36.0 & 83.0 & 138.0 & 159.0 & 62.62\end{array}$

$\begin{array}{llllllll}0.87 & 0.20 & 0.00 & 0.76 & 0.86 & 1.00 & 1.38 & 22.60\end{array}$

$\begin{array}{llllllll}76.00 & 7.57 & 0.00 & 75.00 & 77.00 & 78.00 & 82.00 & 9.96\end{array}$

$\begin{array}{llllllll}67.8 & 50.1 & 0.0 & 22.0 & 58.0 & 113.0 & 155.0 & 73.92\end{array}$

$\begin{array}{llllllll}69.9 & 22.5 & 0.0 & 54.7 & 74.6 & 90.3 & 100.0 & 32.16\end{array}$

SD: standard deviation; Min: minimum value; Q: quartile; Max: maximum value; CV: coefficient of variation; LW: live weight; ADG: average daily gain; spz: spermatozoa; NAR: normal apical ridge; Profitable ejaculates: ejaculates of normal appearance with an adequate visual motility and concentration (percentage of the total collection attempts).

${ }^{1}$ Testing phase: from 147 to 175 days old; ${ }^{2}$ Production phase: from 175 to 2 years old (maximum);

${ }^{3}$ Visual motilities done by the same technician at each centre. 
Table 2. Relative risks ratio, of changing from zero mating attempts to one, two, three or four successful attempts, per each unit of increase in the standardised variables related to the early development.

\begin{tabular}{|c|c|c|c|c|c|c|c|c|c|}
\hline \multirow{2}{*}{$\begin{array}{l}\text { Standardised } \\
\text { variable }^{1}\end{array}$} & \multicolumn{5}{|c|}{ Number of attempts made } & \multicolumn{4}{|c|}{ P-values } \\
\hline & Zero $^{2}$ & One & Two & Three & Four & One & Two & Three & Four \\
\hline LW 0 days & 1.00 & 0.852 & 0.979 & 0.840 & 0.927 & 0.431 & 0.905 & 0.221 & 0.584 \\
\hline LW 28 days & 1.00 & 1.182 & 1.277 & 1.140 & 1.180 & 0.417 & 0.184 & 0.386 & 0.274 \\
\hline LW 63 days & 1.00 & 1.184 & 1.444 & 1.266 & 1.195 & 0.417 & 0.052 & 0.119 & 0.232 \\
\hline LW 147 days & 1.00 & 1.349 & 1.394 & 1.354 & 1.184 & 0.238 & 0.131 & 0.103 & 0.356 \\
\hline ADG 0-28 days & 1.00 & 1.207 & 1.294 & 1.165 & 1.198 & 0.360 & 0.161 & 0.314 & 0.235 \\
\hline ADG 28-63 days & 1.00 & 1.125 & 1.437 & 1.281 & 1.146 & 0.590 & 0.074 & 0.117 & 0.371 \\
\hline ADG 63-147 days & 1.00 & 1.227 & 1.101 & 1.109 & 1.023 & 0.398 & 0.634 & 0.547 & 0.894 \\
\hline
\end{tabular}

${ }^{1} \mathrm{LW}=$ live weight and $\mathrm{ADG}=$ average daily gain. ${ }^{2}$ Zero represents the reference level to which the pairwise comparisons were performed. 
Table 3. Linear effect of early growth traits ${ }^{1}$ on semen parameters during the testing phase (estimate \pm standard error).

\begin{tabular}{|c|c|c|c|c|c|c|c|}
\hline & $\begin{array}{l}\text { LW at birth }{ }^{2} \\
\quad(\times 10 \mathrm{~g})\end{array}$ & $\begin{array}{l}\text { LW at weaning } \\
\quad(\times 100 \mathrm{~g})\end{array}$ & $\begin{array}{c}\text { LW at rearing } \\
\text { onset } \\
(\times 1000 \mathrm{~g})\end{array}$ & $\begin{array}{l}\text { LW at rearing end } \\
\qquad \times 1000 \mathrm{~g})\end{array}$ & $\begin{array}{l}\text { ADG lactation } \\
(\times 10 \mathrm{~g})\end{array}$ & $\begin{array}{l}\text { ADG fattening } \\
\qquad(\times 10 \mathrm{~g})\end{array}$ & $\begin{array}{l}\text { ADG rearing } \\
\quad(\times 10 \mathrm{~g})\end{array}$ \\
\hline Volume (mL) & $0.019 \pm 0.009^{*}$ & $0.013 \pm 0.007$ & $0.069 \pm 0.036$ & $0.057 \pm 0.024^{*}$ & $0.037 \pm 0.021$ & $0.024 \pm 0.017$ & $0.020 \pm 0.023$ \\
\hline Concentration $\left(\log _{10} 10^{6} \mathrm{spz} / \mathrm{mL}\right)$ & $0.038 \pm 0.015^{*}$ & $0.043 \pm 0.012^{* * *}$ & $0.210 \pm 0.061^{* * *}$ & $0.046 \pm 0.042$ & $0.123 \pm 0.036^{* * *}$ & $0.071 \pm 0.030^{*}$ & $-0.048 \pm 0.039$ \\
\hline$\left(10^{6} \mathrm{spz} / \mathrm{mL}\right)$ & 1.091 & 1.104 & 1.622 & 1.112 & 1.327 & 1.178 & 0.895 \\
\hline Production $\left(\log _{10} 10^{6} \mathrm{spz} / \mathrm{ejac}\right)$ & $0.051 \pm 0.018^{* * *}$ & $0.055 \pm 0.015^{* * *}$ & $0.286 \pm 0.072^{* * *}$ & $0.092 \pm 0.050$ & $0.158 \pm 0.043^{* * *}$ & $0.102 \pm 0.036^{* *}$ & $-0.038 \pm 0.046$ \\
\hline$\left(10^{6} \mathrm{spz} / \mathrm{ejac}\right)$ & 1.125 & 1.135 & 1.932 & 1.236 & 1.439 & 1.265 & 0.916 \\
\hline \multirow[t]{2}{*}{ Motility } & $0.123 \pm 0.059^{*}$ & $0.155 \pm 0.049^{* *}$ & $0.870 \pm 0.248^{* * *}$ & $0.238 \pm 0.157$ & $0.447 \pm 0.142^{* *}$ & $0.321 \pm 0.122^{* *}$ & $0.000 \pm 0.146$ \\
\hline & 1.131 & 1.168 & 2.387 & 1.269 & 1.564 & 1.379 & 1.000 \\
\hline NAR $(\%)$ & $0.000 \pm 0.023$ & $-0.001 \pm 0.019$ & $0.003 \pm 0.095$ & $-0.003 \pm 0.063$ & $-0.002 \pm 0.056$ & $0.003 \pm 0.046$ & $-0.006 \pm 0.058$ \\
\hline Spz abnormalities (\%) & $-0.003 \pm 0.004$ & $-0.003 \pm 0.004$ & $-0.024 \pm 0.018$ & $0.001 \pm 0.012$ & $-0.007 \pm 0.011$ & $-0.012 \pm 0.009$ & $0.010 \pm 0.011$ \\
\hline
\end{tabular}

${ }^{1}$ The change in each growth trait needed to obtain the estimated change for the different semen parameter is shown in brackets.

${ }^{2}$ Standardised weight at birth (corrected by milk spot presence).

${ }^{3}$ Motility of the ejaculate presented as a binomial variable: 0 , motile sperm below $65 \% ; 1$, motile sperm above $65 \%$. Odds: increase of relative probability to be classified as 1

(motile sperm above $65 \%$ ) per unit of proposed LW or ADG change (see ${ }^{\mathrm{a}}$ ).

LW: live weight; ADG: average daily gain; NAR: normal apical ridge; spz: spermatozoa; ejac: ejaculate.

Weaning (28 days old); Rearing onset (63 days old); Rearing end (147 days old).

${ }^{*} \mathrm{P}<0.05 ;{ }^{* *} \mathrm{P}<0.01 ;{ }^{* * *} \mathrm{P}<0.001$. 


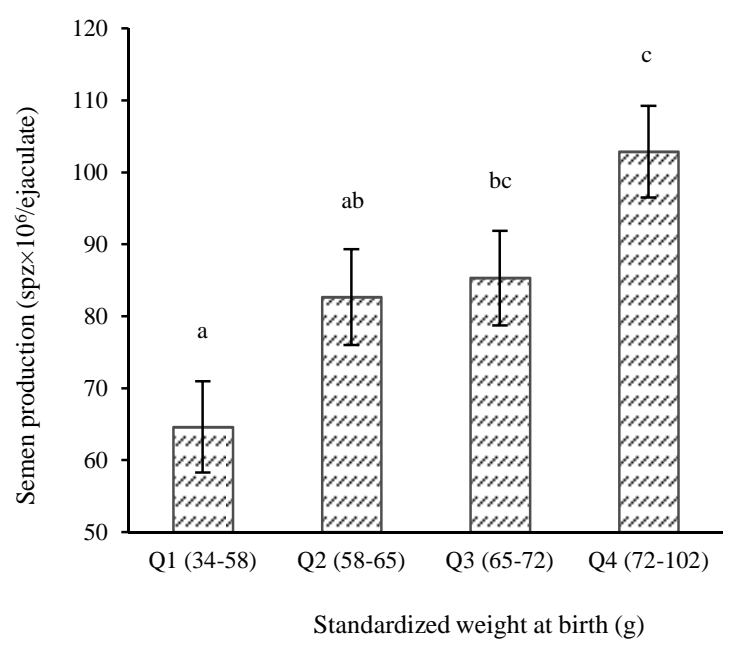

(b)

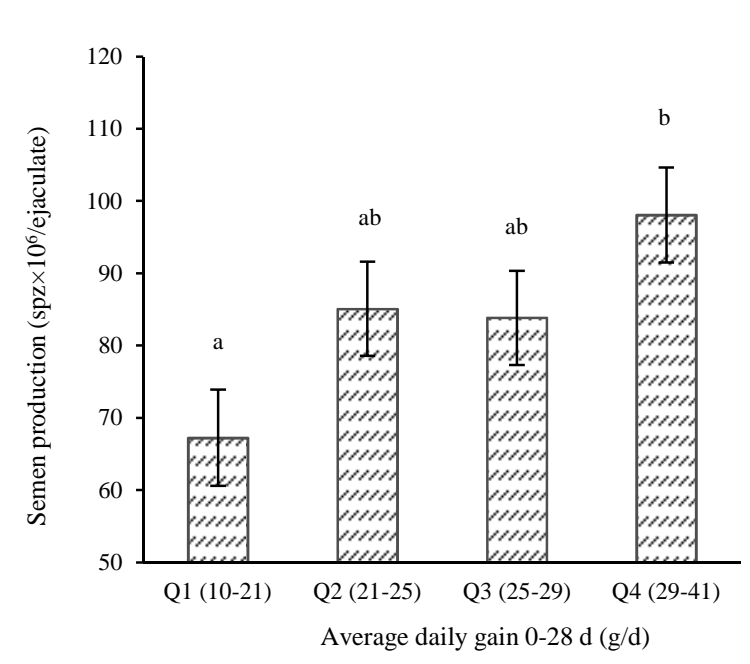

(c)

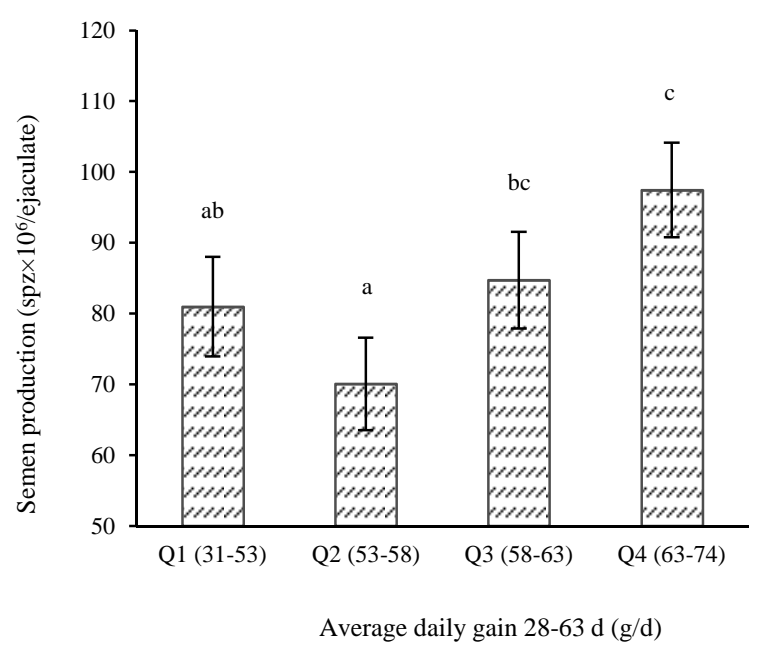

Figure 1. Average semen production (spermatozoon $\times 10^{6}$ per ejaculate) according to the classification by quartiles of the population for: (a) standardised weight at birth (corrected according to milk spot presence), (b) average daily gain from 0 to 28 days of age and (c) average daily gain from 28 to 63 days of age. 


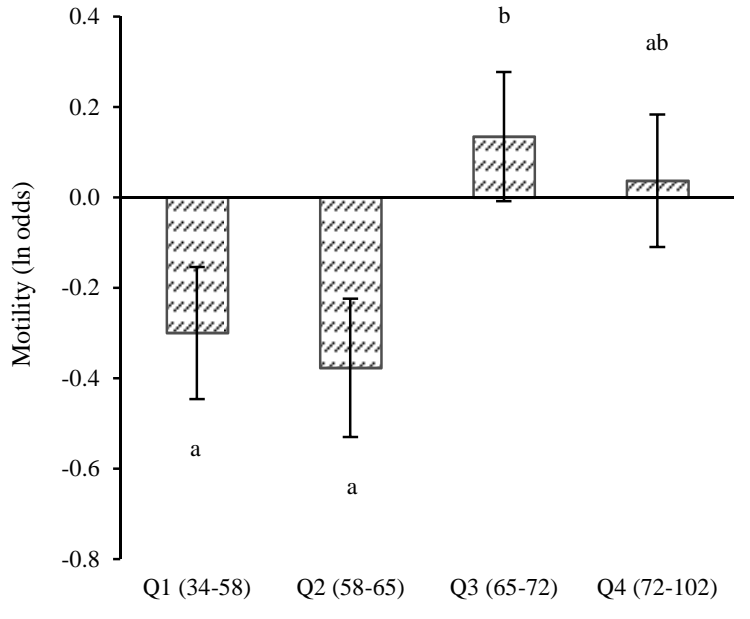

Standardised weight at birth $(\mathrm{g})$

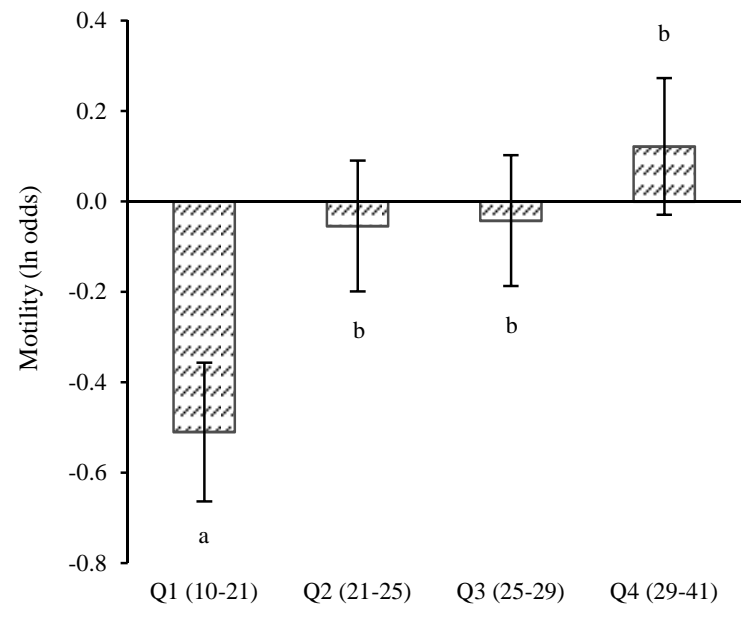

Average daily gain $0-28 \mathrm{~d}(\mathrm{~g} / \mathrm{d})$

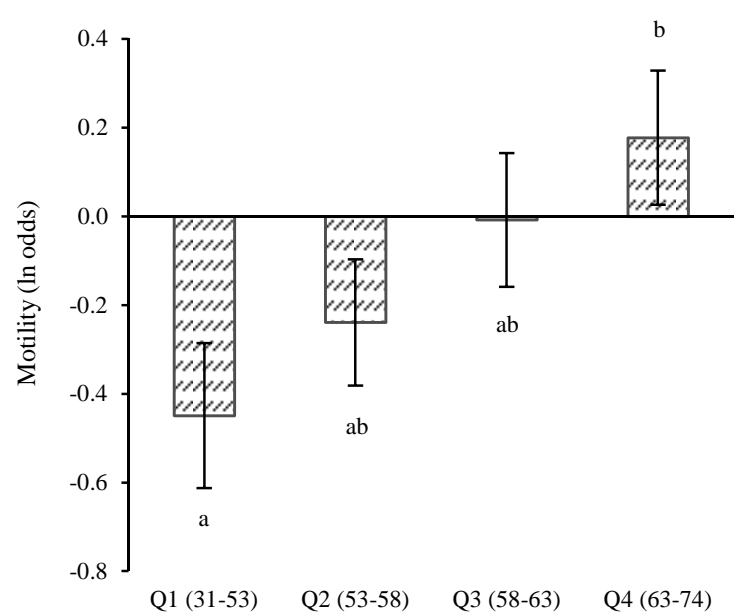

Average daily gain $28-63 \mathrm{~d}(\mathrm{~g} / \mathrm{d})$

Figure 2. Average motility (ln odds) according to the classification by quartiles of the population for: (a) standardised weight at birth (corrected by milk spot presence), (b) average daily gain from 0 to 28 days of age and (c) average daily gain from 28 to 63 days of age. Motility of the ejaculate was presented as a binomial variable: 0 , motile sperm below $65 \% ; 1$, motile sperm above $65 \%$. Odds: increase of relative probability to be classified as 1 (motile sperm above $65 \%$ ). 
Table 4. Linear effect of early growth traits ${ }^{1}$ on semen parameters during the productive phase (estimate \pm standard error)

\begin{tabular}{|c|c|c|c|c|c|c|c|}
\hline & $\begin{array}{l}\text { LW at birth }{ }^{2} \\
\qquad(\times 10 \mathrm{~g})\end{array}$ & $\begin{array}{l}\text { LW at weaning } \\
\qquad(\times 100 \mathrm{~g})\end{array}$ & $\begin{array}{l}\text { LW at rearing onset } \\
\qquad(\times 1000 \mathrm{~g})\end{array}$ & $\begin{array}{l}\text { LW at rearing end } \\
(\times 1000 \mathrm{~g})\end{array}$ & $\begin{array}{l}\text { ADG lactation } \\
\quad(\times 10 \mathrm{~g})\end{array}$ & $\begin{array}{l}\text { ADG fattening } \\
(\times 10 \mathrm{~g})\end{array}$ & $\begin{array}{l}\text { ADG rearing } \\
\qquad(\times 10 \mathrm{~g})\end{array}$ \\
\hline Average volume (mL) & $0.000 \pm 0.007$ & $0.000 \pm 0.005$ & $-0.008 \pm 0.026$ & $-0.030 \pm 0.018$ & $0.000 \pm 0.015$ & $-0.005 \pm 0.012$ & $-0.028 \pm 0.016$ \\
\hline Average motility (\%) & $0.029 \pm 0.102$ & $0.101 \pm 0.077$ & $0.492 \pm 0.370$ & $0.119 \pm 0.243$ & $0.298 \pm 0.226$ & $0.168 \pm 0.177$ & $-0.198 \pm 0.219$ \\
\hline Profitable ejaculates (n) & $-2.036 \pm 2.115$ & $-2.314 \pm 1.590$ & $-3.261 \pm 7.709$ & $-10.945 \pm 5.219$ & $-6.584 \pm 4.607$ & $1.399 \pm 3.682$ & $-10.057 \pm 4.699^{*}$ \\
\hline Profitable ejaculates (\%) & $-0.208 \pm 0.788$ & $-0.804 \pm 0.592$ & $-2.911 \pm 2.867$ & $-5.829 \pm 1.898^{* *}$ & $-2.374 \pm 1.715$ & $-0.672 \pm 1.371$ & $-4.856 \pm 1.713^{* *}$ \\
\hline
\end{tabular}

${ }^{1}$ The change in each growth trait needed to obtain the estimated change at the different semen parameter is shown in brackets.

${ }^{2}$ Standardised weight at birth (corrected by milk spot presence).

LW: live weight; Weaning (28 days old); Rearing onset (63 days old); Rearing end (147 days old).

Average volume: average value of ejaculates with normal aspect; Average motility: average value of ejaculates with normal aspect.

Profitable ejaculates: ejaculates of normal appearance with an adequate visual motility and concentration (percentage of the total number of attempts to extract semen.).

$\mathrm{P}<0.05 ;{ }^{*} \mathrm{P}<0.01$. 


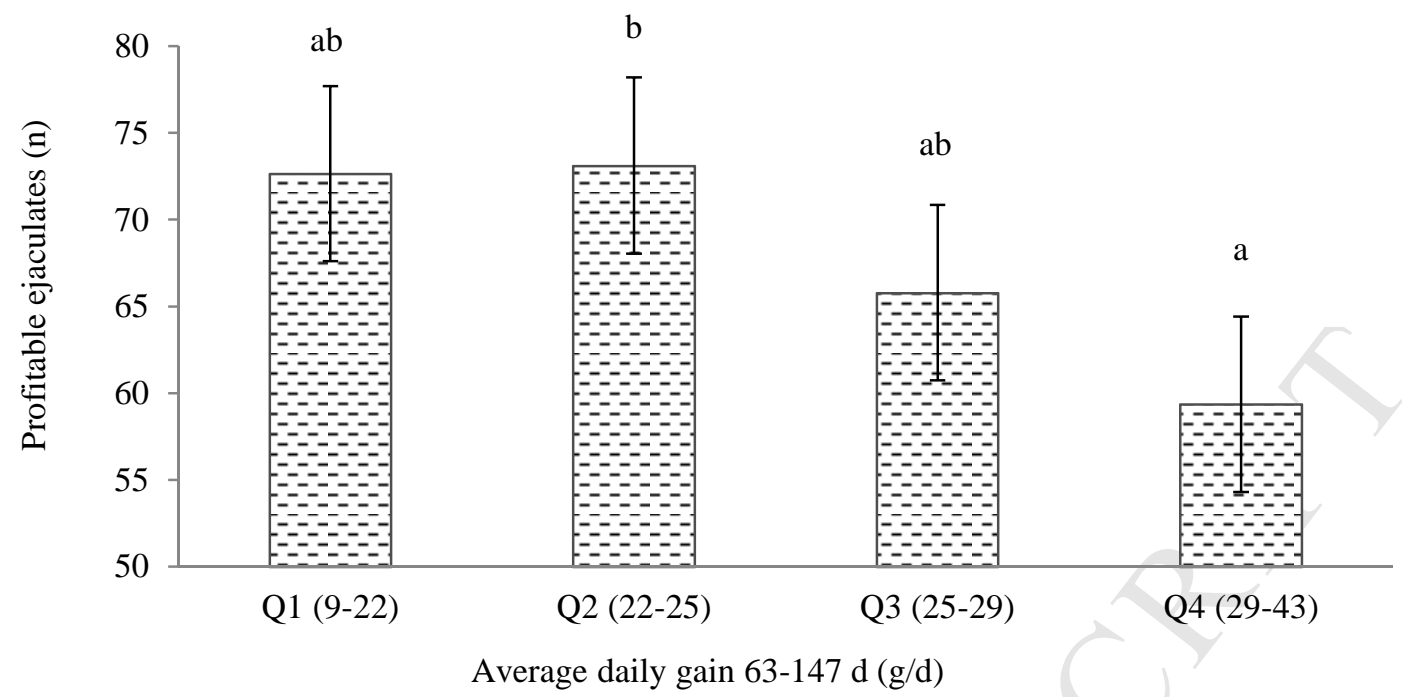

Figure 3. Number of profitable ejaculates (ejaculates of normal appearance with an adequate visual motility and concentration) according to the classification by quartiles of the average daily gain from 63 to 147 days of age. 
Table 5. Influence of the early development variables (standardised variables) on the hazard ratio of death or culling of males during its productive life. Values above one represents an increment on the hazard ratio and therefore a reduction on the productive life.

\begin{tabular}{lcccc}
\hline $\begin{array}{l}\text { Standardised } \\
\text { variable }^{1}\end{array}$ & $\begin{array}{c}\text { Hazard } \\
\text { ratio }\end{array}$ & $\begin{array}{c}\text { 95\% Confidence } \\
\text { interval }\end{array}$ & P-value & $\begin{array}{c}\text { Likelihood } \\
\text { ratio test }^{2}\end{array}$ \\
\hline LW 0 days & 1.067 & {$[0.93-1.22]$} & 0.34 & 0.30 \\
LW 28 days & 1.146 & {$[1.00-1.31]$} & 0.04 & 0.04 \\
LW 63 days & 1.039 & {$[0.91-1.19]$} & 0.57 & 0.60 \\
LW 147 days & 1.175 & {$[1.02-1.35]$} & 0.03 & 0.03 \\
ADG 0-28 days & 1.146 & {$[1.00-1.31]$} & 0.04 & 0.04 \\
ADG 28-63 days & 0.965 & {$[0.84-1.10]$} & 0.59 & 0.60 \\
ADG 63-147 days & 1.162 & {$[1.02-1.33]$} & 0.03 & 0.03
\end{tabular}

${ }^{1} \mathrm{LW}=$ live weight and $\mathrm{ADG}=$ average daily gain. ${ }^{2}$ P-values of likelihood ratio test for the null hypothesis that all covariates of the implemented model are equal to zero. 
(a)

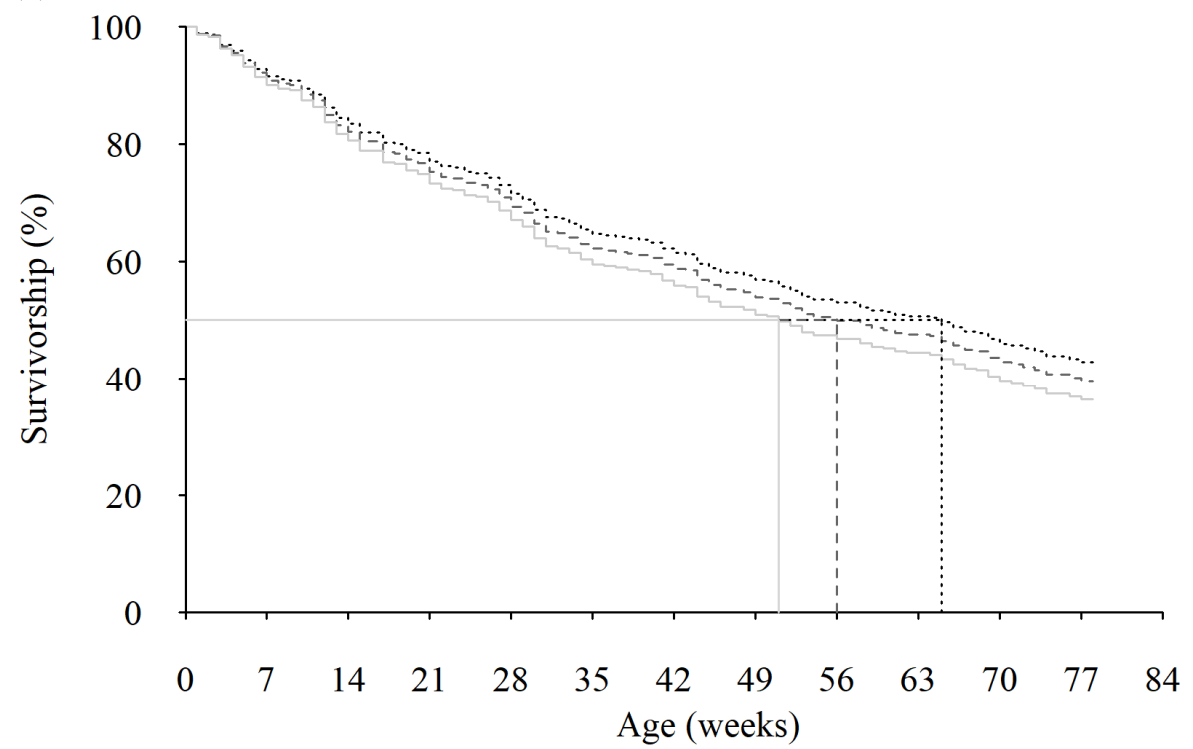

(b)

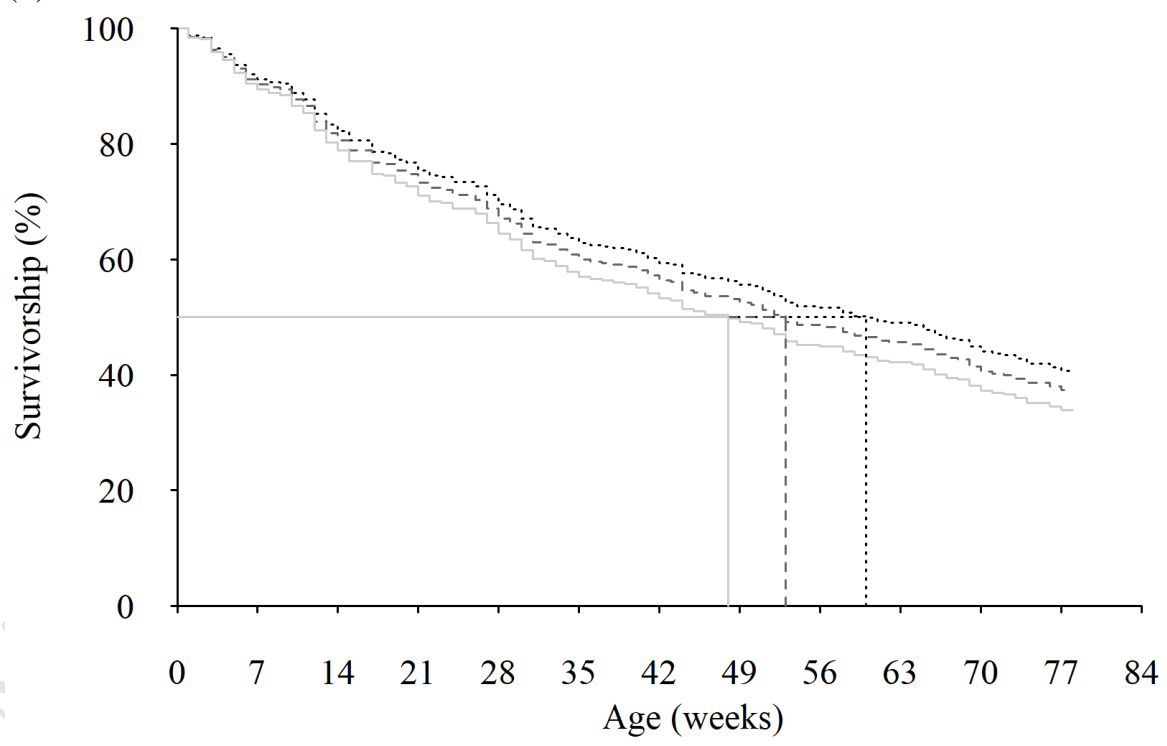

Figure 4. Survivorship estimation (percentage of live animals) across time (age in weeks) according to the live weight at different points of development: a) theoretical males with different live weight at weaning (light grey: $650 \mathrm{~g}$; dark grey: 750 g; black: 850 g) and vertical segments represent the median survival time: 65,56 and 51 weeks, respectively; b) theoretical males with different live weight at the end of the rearing period (light grey: 4600 g; dark grey: 4900 g; black: 5200 g) and vertical segments represent the median survival time: 60, 53 and 48 weeks, respectively. 


\section{Highlights}

Body development of young rabbit males influences on their semen performance and lifespan.

Growth until 2-months age had only effects at the beginning of males' reproductive life.

Excessive growth at rearing have negative consequences on males' semen in long-term.

Excessive growth at lactation or rearing could have negative effects on males' lifespan. 